\title{
Occupational solar UV exposure in construction workers in Italy: results of a one-month monitoring with personal dosimeters
}

\author{
Alberto Modenese \\ Dept. of Biomedical, Metabolic and \\ Neural Sciences \\ University of Modena \& Reggio Emilia \\ Modena, Italy \\ alberto.modenese@unimore.it
}

Swen Malte John

Dept. of Dermatology, Environmental

Medicine and Health Theory

University of Osnabrïck

Osnabrück, Germany

sjohn@uni-osnabrueck.de

\author{
Fabriziomaria Gobba \\ Dept. of Biomedical, Metabolic and \\ Neural Sciences \\ University of Modena \& Reggio Emilia \\ Modena, Italy \\ fabriziomaria.gobba@unimore.it \\ Pietro Sartorelli \\ Dept. of Medical Biotechnology - Unit \\ of Occupational Medicine \\ University of Siena \\ Siena, Italy \\ pietro.sartorelli@unisi.it
}

\author{
Valentina Paolucci \\ Dept. of Prevention, Health and Safety \\ Unit \\ AUSL South-East Tuscany \\ Grosseto, Italy \\ valentina.paolucci@uslsudest.toscana.it

Marc Wittlich
Inst. for Occupational Safety and
Health
German Social Accident Insurance,
Sankt Augustin, Germany
marc.wittlich@dguv.de

\begin{abstract}
Occupational exposure to solar UV radiation (UVR) is relevant in the construction sector. We performed a one month monitoring period in late spring of direct individual solar UVR exposure measurements in a group of three construction workers from the Tuscany Italian region, using the GENESIS-UV system for personal dosimetry and for the collection of long-term exposure data in a centralized dataset. Then, we compared personal UVR exposure data with the environmental erythemal dose in the same days in clear-sky conditions. The individual solar UVR exposures of the construction workers in the period between $22^{\text {nd }}$ May and $22^{\text {nd }}$ June 2017 in Tuscany varied between 85.5 and $1556.8 \mathrm{~J} / \mathrm{m} 2$, while the average daily exposure considering all the three workers resulted $573.3 \mathrm{~J} / \mathrm{m} 2$. The percentage between individual vs environmental exposure varied from 2.7 up to $31.2 \%$, resulting 12.2 on average. Of the total amount of 40 days/worker measured we detected exposure levels above the $100 \mathrm{~J} / \mathrm{m} 2$ proposed limit value in 39 days/worker, with exceeding of the limit up to ten times per day, more than five times on average. In terms of cumulative UVR exposure, the construction workers received on average a total one month exposure, based on 21 working days, of $12 \mathrm{~kJ} / \mathrm{m} 2$, and we estimated an annual exposure of about $70 \mathrm{~kJ} / \mathrm{m2}$, approximately corresponding to 700 Standard Erythemal Doses. Our data show that the exposure levels of the Italian construction workers are very high in late spring, systematically exceeding the limit values. These UVR exposure levels can be considered potentially dangerous, in particular if associated with relevant cumulative annual UV doses received at the body, which are related to an increased risk of adverse effects, including skin cancers. Accordingly, a big effort is needed, to urgently reduce occupational solar UVR exposure in the construction sector, improving the application of preventive measures.
\end{abstract}

Keywords-ultraviolet radiation, occupational exposure, dosimetry, construction industry, solar radiation

\section{INTRODUCTION}

Solar radiation (SR) is a well known and diffused occupational physical risk: it relates to incoherent optical radiations exposure, that are ultraviolet radiation (UVR), visible radiation and infrared radiation. Among optical radiation, UVR is the most hazardous component, as it is

The European Academy of Dermatology and Venereology supported this study through project no. 18 ,Joint scientific implementation and evaluation of the Healthy Skin@Work Campaign, sub-campaign skin Cancer: Safe Work Under the Sun" project able to induce the main and most severe adverse health effects in humans, including cancers $[1,2]$. UVR can be further divided in UV-C (wavelength; $\lambda=100-280 \mathrm{~nm}$ ), UV-B $(\lambda=280-315 \mathrm{~nm})$ and UV-A $(\lambda=315-400 \mathrm{~nm})$, but the solar radiation spectrum at the earth's surface is quite different from that emitted by the sun, mainly due to the shielding effect of the ozone, blocking all the wavelengths shorter than $290 \mathrm{~nm}$, i.e., all the UV-C and the majority of UV-B $[1,2]$.

Construction workers are currently considered "outdoor workers", i.e. workers who spend most of their working time outside, even if the variety of working tasks and the specific characteristics of the jobs and of the construction sites may result in highly variable habits of outdoor work $[1,2]$. Scientific data show that construction workers can be significantly exposed to high levels of UVR, mainly due to SR. Other possible sources of UVR exposure in the construction sector can be welding activities, even if this exposure can be relevant for a very specific sub-group and a minority of the total number of construction workers generally employed $[1,2]$.

UVR has a limited penetration depth in biological tissues and its biological interaction mechanisms are mainly "photochemical", possibly inducing short-term and longterm effects in the eyes [3-5] and in the skin of the exposed subjects [6-8]. Photochemical effects are related to the absorption of the UV photons by specific target molecules of the tissues, defined chromophores, and the effect is cumulative. Accordingly the resulting effects are related to the total dose received, and we can expect consequences both in case of high short-term exposure and of less intense but prolonged UV exposure [9].

A particular issue, relevant for a correct evaluation of the occupational solar UV risk, is that it's quite complicated to provide a reliable estimate of cumulative UV exposure in workers [10]. In fact, most published studies report measures of solar UVR representing an acute exposure of few hours/days [9-11]. These measures can be expressed in terms of radiant energy (Joules -J-) and irradiance (Watts per square meter $-W / m 2$ ), and their effective quantities, i.e. the ability to induce appreciable effects, most commonly skin erythema: usually in UV dosimetry studies of outdoor 
workers data are reported in "Standard Erythemal Dose" (SED), representing an erythemal radiant UV exposure of 100 Joule $/ \mathrm{m}^{2}$, standardized for individual UV sensitivity [911]. Nevertheless, these short-term measurements are not adequate for an evaluation of the overall UV risk during different outdoor working activities performed in various settings, as it happens for construction workers. Few studies have applied semi-quantitative methods to evaluate longterm UV exposure integrating subjective information and objective measurements [9,-11]. Recently, Wittlich et al. proposed a new method and elaborated a specific algorithm for the estimate of annual UV exposure in groups of outdoor workers [12], and this method has been tested across Europe with a UV measurement campaign involving a large group of construction workers monitored for a long period in different countries $[13,14]$.

Aim of the present study is to report the first Italian data of a one month full occupational solar UVR exposure monitoring with personal dosimeters of a group of construction workers, comparing the measurements with available environmental data.

\section{MATERIALS AND METHODS}

\section{A. Study population and study context}

We present here original data obtained in Italy based on the protocol of a larger international study performed in five different European countries [14]. The original occupational group involved in this study was composed of four male construction workers employed in a small company from the province of Siena, in Tuscany region (latitude $=43^{\circ} 19^{\prime} \mathrm{N}$; longitude $=11^{\circ} 19^{\prime} \mathrm{E}$ ). The workers were engaged in different building activities but, especially during the spring and summer, due to the favorable weather conditions, mainly in outdoor activities as roofing and exterior structure construction, while interior activities, as plaster and finishing, are more usual in autumn and winter. The objective of the study was explained to the workers, and it was clarified that the participation was on a voluntary basis. All the subjects agreed to participate and an informed consensus was collected.

The measurement campaign was programmed in MayJune 2017, considered representative of the late springsummer period, i.e. a part of the year with higher UV solar irradiation in Italy. Unfortunately, due to different technical and organizational problems in the collection of the data, a number of measurements went lost in particular in one of the workers (only 5 valid days were obtained during the whole period): this subject was therefore excluded from the study. Accordingly, we present here measurements data obtained in three male construction workers followed for their individual solar UVR exposure for about 30 days, starting on the 22 of May and ending on the 22 of June 2017. During this period, excluding Saturdays and Sundays and an Italian National Holiday (2nd of June) the total working days were 23. Multiplying this number for the three workers, we obtain the theoretical maximum of days/worker, that is 69 .

\section{B. Method to measure occupational solar UVR exposure of construction workers}

The occupational solar UVR exposure monitoring was performed with the GENESIS-UV (GENeration and Extraction System for Individual exposure) methodology (Fig. 1).

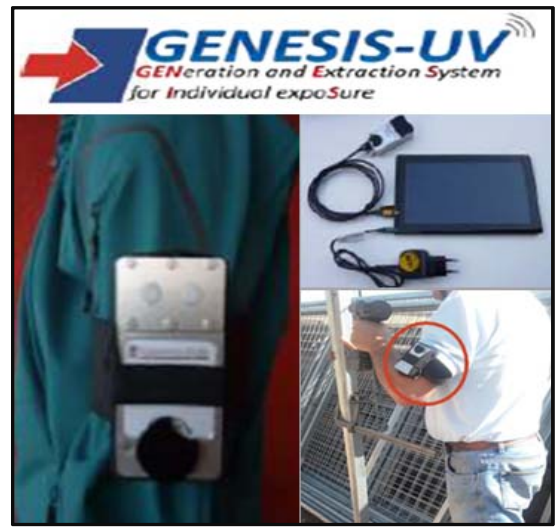

Fig. 1. The GENESIS-UV system for long term occupational UV exposure monitoring

GENESIS-UV consists of an electronic data logger dosimeter, a tablet PC for data storage and transmission, and accessory parts. The electronic dosimeters "X-2012-10" (Gigahertz, Turkenfeld, Germany) register the UV irradiance in the UVA and UVB/C regions separately. It is a two cell erythema irradiance detector, with two sensors: a) an UV-A sensor with a spectral responsivity range from 320 to $400 \mathrm{~nm}$, with a responsivity of $0.6 \mu \mathrm{A} /\left(\mathrm{W} / \mathrm{m}^{2}\right)$ and a measurement range from $2 \mathrm{~mW} / \mathrm{m}^{2}$ to $30 \mathrm{~W} / \mathrm{m}^{2}$; b) an $\mathrm{UV}$ $\mathrm{BC}$ sensor with a spectral responsivity range from $250 \mathrm{~nm}$ to $320 \mathrm{~nm}$, a responsivity of $3 \mathrm{nA} /\left(\mathrm{W} / \mathrm{m}^{2}\right)$ and a measurement range from $0.03 \mathrm{~W} / \mathrm{m}^{2}$ to $5500 \mathrm{~W} / \mathrm{m}^{2}$.

We used 3 dosimeters: each worker was equipped with a dosimeter worned at the left upper arm during working hours, usually from 9.00 to 5.00 p.m. (Fig. 1). Once a week the dosimeter had to be connected to the tablet PC to transfer the data to the data server in Germany.

Individual exposure of the workers was compared to the the total environmental erythemal UV dose in clear sky conditions during the same day, available through the database of the European Space Agency (ESA). As data for the city of Siena were not available, we considered as a proxy the data referred to Rome, quite close to Siena (230 kilometers) and comparable both in latitude and altitude (http://www.temis.nl/uvradiation/archives/v2.0/overpass/uv Rome_Italy.dat ).

\section{RESULTS}

We obtained valid data on personal solar UVR exposure of the three construction workers monitored, during the onemonth period May $22^{\text {nd }}-$ June $22^{\text {nd }} 2017$. As anticipated, the theoretical maximum number of days/worker measurable in the period is 69 but, due to different types of technical and organizational problems, a total of 40 individual daily solar UVR exposure are available, representing the $58 \%$ of the maximum theoretical. On the other hand, considering that the measurements of exposure during the working days were collected from three different workers, at the end we have data on occupational UV exposure of at least one worker during the large majority of the days: 21 out of $23(91.3 \%)$.

The results of the daily individual solar UVR exposure measurements, and the total environmental erythemal UV dose in clear-sky conditions during the monitored period are presented in Figure 2. 


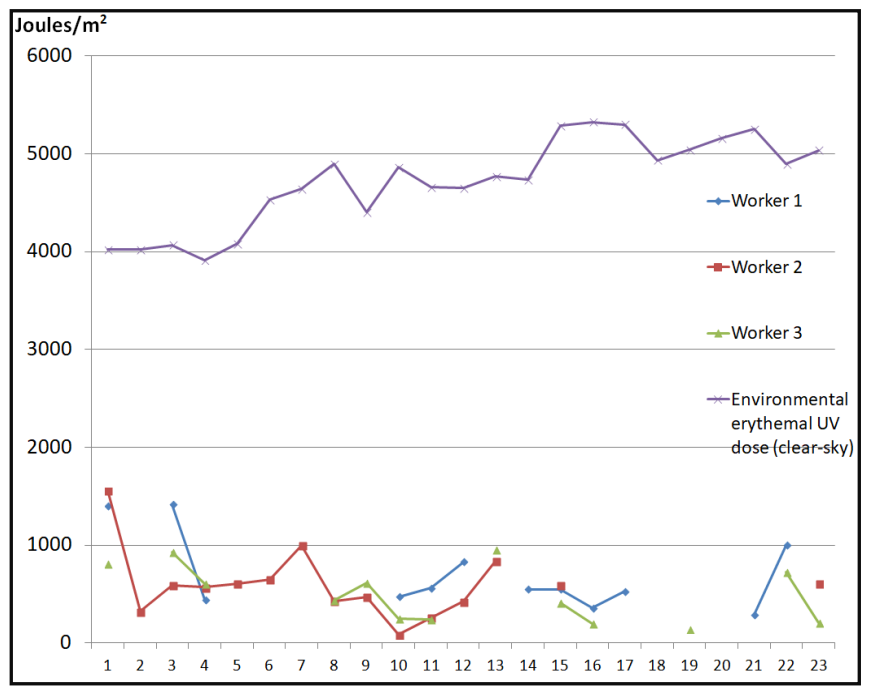

Fig. 2. Results of the daily individual solar UVR exposure measurements obtained in the period considered $\left(22^{\text {nd }}\right.$ May $-22^{\text {nd }}$ June $2017 ; 23$ working days) in Siena (Italy), compared to approximate total environmental erythemal UV dose in clear-sky conditions. All data are reported in Joules per square meter $(\mathrm{J} / \mathrm{m} 2)$. In the $x$ axis the number of the working day (not the date), is reported.

In Worker 1 individual exposure ranged between 287.6 and $1414.7 \mathrm{~J} / \mathrm{m} 2$, while in Worker 2 personal levels between 85.5 and $1556.8 \mathrm{~J} / \mathrm{m} 2$ were measured, and finally, in Worker 3 the UVR dose received varied between 138.3 and 950.0 $\mathrm{J} / \mathrm{m} 2$. During the same period, environmental erythemal UV dose in clear sky conditions was much higher: between 3911 $\mathrm{J} / \mathrm{m} 2$ registered at the end of May and $5288 \mathrm{~J} / \mathrm{m} 2$ in the mid of June (Fig. 2).

In Table I, the daily UVR exposure levels related to the occupational activity of the construction workers are reported, as the mean of the individual data of the three workers (when avaialble) or, if not possible, as the mean of the measurments of two subjects or, in a few cases, from only one worker measurements. These values are compared to the total amount of environmental erythemal UVR dose in clear sky conditions during the same day obtained from the European Space Agency.

The percentage of the environmental UVR received by the workers varied between the $2.7 \%$ (mid of June) and the $31.2 \%$ (end of May). On average, the daily exposure of the workers during working days in the monitored month resulted $573.3 \mathrm{~J} / \mathrm{m} 2 \quad(\mathrm{SD}=285.1)$. As the mean daily environmental erythemal dose during the same period was $4685.4 \mathrm{~J} / \mathrm{m} 2(\mathrm{SD}=450.3)$, the average proportion of personal dose received by the monitored construction workers compared to ambient exposure was of $12.2 \%$ (Tab. I).

In terms of cumulative solar UVR exposure, the total exposure received by the Worker 1 during the monitored month was of $8397.9 \mathrm{~J} / \mathrm{m}^{2}$ in 12 days. In Worker 2 the cumulative exposure was $9004.2 \mathrm{~J} / \mathrm{m}^{2}$ in 15 days, while Worker 3 received $6507.4 \mathrm{~J} / \mathrm{m}^{2}$ in 13 days. Considering all the 21 days for which exposure data are avalable from at least one worker, we have calculated an estimate of the cumulative UV exposure of an Italian construction worker in Tuscany during a spring month as high as $12039.9 \mathrm{~J} / \mathrm{m}^{2}$ on average (Tab. I).
TABLE I. INDIVIDUAL EXPOSURE (ON AVERAGE AND CUMULATIVE) TO SOLAR UV RADIATION OF A GROUP OF THREE CONSTRUCTION WORKERS FROM TUSCANY (ITALY) IN A ONE MONTH PERIOD BETWEEN 22ND MAY AND 22ND JUNE 2017, COMPARED TO THE RESPECTED ENVIRONMENTAL ERYTHEMAL UV DOSE IN CLEAR-SKY CONDITIONS

\begin{tabular}{|c|c|c|c|}
\hline \multirow[b]{2}{*}{$\begin{array}{l}\text { Working } \\
\text { days }^{\mathrm{a}}\end{array}$} & \multicolumn{3}{|c|}{ Solar UVR exposure in Joules per square meter $\left(\mathrm{J} / \mathbf{m}^{2}\right)$} \\
\hline & $\begin{array}{c}\text { Average daily solar } \\
\text { exposure of the } \\
\text { three construction } \\
\text { workers }{ }^{b}\end{array}$ & \begin{tabular}{|c|} 
Environmental daily \\
erythemal $U$ V dose \\
(clear-sky \\
conditions)
\end{tabular} & $\begin{array}{l}\text { Percentage of } \\
\text { individual vs. } \\
\text { environmental } \\
\text { exposure (\%) }\end{array}$ \\
\hline 1 & 1256.0 & 4021.0 & 31.2 \\
\hline 2 & 321.3 & 4019.0 & 8.0 \\
\hline 3 & 976.5 & 4068.0 & 24.0 \\
\hline 4 & 539.3 & 3911.0 & 13.8 \\
\hline 5 & 609.5 & 4079.0 & 14.9 \\
\hline 6 & 649.8 & 4533.0 & 14.3 \\
\hline 7 & 1000.7 & 4642.0 & 21.6 \\
\hline 8 & 434.7 & 4896.0 & 8.9 \\
\hline 9 & 541.5 & 4402.0 & 12.3 \\
\hline 10 & 268.4 & 4865.0 & 5.5 \\
\hline 11 & 354.8 & 4660.0 & 7.6 \\
\hline 12 & 627.4 & 4652.0 & 13.5 \\
\hline 13 & 892.5 & 4768.0 & 18.7 \\
\hline 14 & 549.7 & 4733.0 & 11.6 \\
\hline 15 & 518.5 & 5288.0 & 9.8 \\
\hline 16 & 278.6 & 5326.0 & 5.2 \\
\hline 17 & 526.8 & 5302.0 & 9.9 \\
\hline 18 & 138.3 & 5041.0 & 2.7 \\
\hline 19 & 287.6 & 5252.0 & 5.5 \\
\hline 20 & 863.6 & 4899.0 & 17.6 \\
\hline \multirow[t]{3}{*}{21} & 404.4 & 5036.0 & 8.0 \\
\hline & $\begin{array}{c}\text { Average daily solar } \\
\text { exposure of the } \\
\text { construction } \\
\text { workers in one } \\
\text { month } \pm \text { standard } \\
\text { deviation } \\
\end{array}$ & \begin{tabular}{|c|} 
Average \\
environmental daily \\
erythemal $U V$ dose \\
(clear-sky \\
conditions) in one \\
month
\end{tabular} & $\begin{array}{c}\text { Average } \\
\text { percentage of } \\
\text { individual vs. } \\
\text { environmental } \\
\text { exposure (\%) }\end{array}$ \\
\hline & $573.3 \pm 285.1$ & $4685.4 \pm 458.1$ & $12.2 \%$ \\
\hline & $\begin{array}{c}\text { Cumulative solar } \\
\text { exposure of a } \\
\text { construction worker } \\
\text { from Tuscany in a } \\
\text { spring month }\end{array}$ & \multicolumn{2}{|c|}{$\begin{array}{c}\text { Cumulative environmental erythemal } \\
\text { UV dose (clear-sky conditions) in } \\
\text { Tuscany in a spring month }\end{array}$} \\
\hline & 12039.9 & \multicolumn{2}{|c|}{98393} \\
\hline
\end{tabular}

a. Working days in the period $22^{\text {nd }}$ May-22 $2^{\text {nd }}$ June 2017 are only 21, as all Saturdays and Sundays were excluded, as well as $2^{\text {nd }}$ June (national holiday) and $15^{\text {th }}$ and $19^{\text {th }}$ June, as we collected no personal UVR exposure measurements in that dates);

b. Mean individual daily exposure of the three workers monitored, or of two workers in case of a missing measurement; in case only the exposure of a single worker was available, this is the reported value in the cell

\section{DISCUSSION AND CONCLUSIONS}

According to our results, construction workers have a significantly high occupational UVR exposure from solar radiation. Our data were obtained in the central part of Italy, and there are no reasons to suppose that cannot be extended to other Italian areas, at least the surrounding regions. This observation is substantially in line with data observed in the same occupational sector in some previous studies in other countries [9], while few data, if any, are available in Italy. Nevertheless, the observed levels are coherent with the few available data published on solar UVR exposure in the same Italian area in workers engaged in other outdoor occupational activities $[15,16]$.

It is not possible to compare the UV exposure levels measured in these workers to occupational limits, as currently in Italy (as in other EU Countries) the only limits in 
force are the International Commission on Non-Ionizing Radiation Protection (ICNIRP) occupational limits values, valid for artificial optical radiation, but not for solar UV [17]. For various reasons, mainly related to the existence of multiple target organs and of different acute and cumulative long term effects, the definition of occupational exposure limit for solar UVR exposure is complex, but an adequate limit level can be considered approximately between 1 and 1.3 Standard Erythemal Doses (SED) per working day [1, 2]; according to ICNIRP, 1 SED is equal to $100 \mathrm{~J} / \mathrm{m} 2$ [17]. If the abovementioned limit level is considered, solar UVR exposure levels measured in the construction workers monitored in this study was largely above the limit during the whole monitored period: considering the mean of all the days the exceeding was in the order of more than five times, with a maximum exceeding during a single day of about ten times (Tab. I). Considering the daily values measured by the dosimeters in each of the three workers, an overcoming of the limit was recorded in 39 out of 40 values. Only in one worker, and for one day only the level was not exceeded, but during the same day the other two workers largely exceeded the limit, suggesting that the low exposure was most probably due to specific, not usual, tasks performed during the day (Fig. 2).

Considering now the comparisons between ambient UVR levels (as available from the ESA database) and individual exposure measured by the meters, our results show a relevant variability. In fact, despite a quite stable erythemal clear-sky UV dose, varying between $3.9 \mathrm{~kJ} / \mathrm{m} 2$ in late May up to about $5.3 \mathrm{~kJ} / \mathrm{m}^{2}$ in June, with a mean value of $4.7 \mathrm{~kJ} / \mathrm{m}^{2}(\mathrm{SD}=4.6$ $\mathrm{kJ} / \mathrm{m}^{2}$ ), the individual exposure of the workers was much more variable: the mean was $0.6 \mathrm{~kJ} / \mathrm{m}^{2}$ (SD $0.3 \mathrm{~kJ} / \mathrm{m}^{2}$ ), and the mean ratio of environment vs personal dose was $12 \%$ but the $90 \%$ of the values ranged between 5 and $20 \%$. A similar quite high variability of individual exposure vs. solar UVR levels is not surprising and was observed in our previous study in a group of fishermen [11] as well as in other personal UVR exposure measurements in construction workers performed in different European countries [13, 14]. As a matter of fact, various factors, of different type, can influence this ratio. In general, it should be considered that the environmental erythemal doses available from the European Space Agency database are referred to a "clearsky" condition, and therefore can be influenced first of all by meteorological conditions such as cloud covering. Moreover, an intrinsic variability of individual solar UVR exposure is related to the specific tasks performed during the day; this is probably more relevant in construction workers compared to other outdoor occupations, as the tasks possibly performed are very different, sometimes almost constantly outdoor (e.g. while roofing), sometimes partly or mainly indoor (e.g. materials preparation or plastering). In the workers sampled in this study the activities performed during the period monitored were mainly outdoor, as roofing and building. A well-known problem in solar UV exposure evaluation is the part of the body to be considered: the top of the head or the shoulders are usually the most exposed areas, while e.g. the exposure of the forehead or of the chest largely depends on the body position. In this study the meters were placed on upper left arm of the workers: even if we are aware that the representativeness of the dose measured in this part depends on the postures adopted (particularly variable for construction workers), the upper left arm was considered a reasonable compromise considering practical problems (as the need to not interfere with working activities) and the possibility of adequately represent the effective dose received by the majority of the body. On the other hand, to solve this issue, recently a promising method to predict the erythemal ultraviolet dose at different body areas has been proposed [18]. Back to the factors possibly responsible of the variability of the ratio between individual UV exposure and environmental solar UVR in construction workers, other examples are differences in the UV reflection of surrounding surfaces, (e.g. the reflection of bare ground is $<5 \%$, compared to $>10 \%$ of limestone or $20 \%$ of white paint), and work organization, in particular the hours of the day spent doing outdoor jobs, the presence of shading, and individual protective habits, including caps and the type of clothing [9, $19,20]$. We are confident that the abovementioned reasons can justify the variability, and that the estimated mean ratio can be considered reasonably representative.

Another interesting observation is that the highest average daily personal UVR exposures were measured at the end of May, when the environmental erythemal dose was lower compared to June, while during this month a tendency to a reduction of individual exposure can be observed, and the values of the ratios between personal and environmental UVR are coherent (Tab I). This observation possibly suggests that when the external temperature is lower and the work conditions seem more affordable for the workers, they tend to work more in the direct sunlight and/or adopting less protective behaviors. The observation is not totally new, as similar findings were reported in an Italian study performed in the same region, Tuscany, that found higher exposure of a group of vineyard workers in spring compared to summer [16]. In terms of prevention, these results are important and should be stressed during workers training, indicating that UVR exposure may be very high also during spring (and autumn) and, for this reason, an adequate work organization, including UV protective clothes, hats and glasses in case, and an adequate information on the UV risk should always be provided to outdoor workers. To better communicate the UV-related risk also at workers' trainings, it should be useful to implement the use of smartphone apps able to predict UV index values, even if it has to be noticed that only few apps are actually consistent with real-time exposure data [21].

The data collected give us the possibility to estimate a cumulative solar UVR exposure for construction workers. The calculated cumulative solar UVR dose received from a construction worker from Tuscany (central Italy) in a one month period $\left(22^{\text {nd }}\right.$ May and $22^{\text {nd }}$ June 2017), representative of late spring, i.e. a period characterized by significant UV incident levels, was approximately $12 \mathrm{~kJ} / \mathrm{m}^{2}$. In the same period, the environmental erythemal UV dose in clear sky conditions was $98 \mathrm{~kJ} / \mathrm{m}^{2}$. Then, using the ESA data (www.temis.nl/uvradiation/archives/v2.0/overpass/uv Rome Italy.dat), and considering approximately 230 working days in the year (after exclusion of weekends and usual holiday periods), a cumulative occupational erythemal annual UV dose of $550-600 \mathrm{~kJ} / \mathrm{m}^{2}$ was calculated. Based on the percentage ratio between individual vs. ambient exposure calculated $(12.2 \%)$, it is possible to estimate the individual 
annual cumulative exposure of an Italian construction worker in central Italy that, in 2017, was of approximately $70 \mathrm{~kJ} / \mathrm{m}^{2}$. The contribution given by the late spring month is of about the $17 \%$ (that seems coherent, considering that the period inducing a significant solar UV exposure covers MarchOctober, with maximum exposure limited to May-September [9]). Considering these data, we can estimate that construction workers in central Italy receive up to 700 SED per year, of which 120 SED in only one late spring month.

This estimation seems very important also in terms of prevention, as it suggests that focusing the main preventive efforts in a relatively short period of the year, it can possibly result in a significant reduction of the cumulative dose received by the workers. Another interesting result is that, if we divide the estimated cumulative annual dose (700 SED) by the number of working days (230), the result is that, on average, also considering winter days, the daily occupational exposure to solar UVR is approximately of $3 \mathrm{SED}$, i.e. about three times the proposed limit.

We have to observe that, even if the study was conducted in central Italy, the results can be reasonably extrapolated to most of the other parts of the country, and the very high cumulative solar UVR occupational exposure estimated for the construction workers highlights the relevant risk of chronic adverse health effects in these workers, particularly (but not limited to) keratinocyte cancers [2, 6, 7, 9].

As a conclusion, the results of this study show a very high exposure to solar UVR in construction workers. During all the working days monitored the proposed occupational limits were systematically exceeded. Moreover, these solar UVR exposure levels result in a very relevant cumulative annual UV dose received at the body, potentially related to an increased risk of adverse health effects, including skin cancers. Accordingly, the implementation of effective protective programs to adequately reduce this unacceptable occupational risk is absolutely relevant and urgent.

\section{ACKNOWLEDGMENT}

We thank the European Academy of Dermatology and Venerology (EADV) and the EU Horizon 2020 COST Action "StanDerm" for the support to the project.

\section{REFERENCES}

[1] T. Tenkate, B. Adam, R.H. Al-Rifai, B.R. Chou, F. Gobba, et al, "WHO/ILO work-related burden of disease and injury: Protocol for systematic reviews of occupational exposure to solar ultraviolet radiation and of the effect of occupational exposure to solar ultraviolet radiation on cataract," Environ. Int., vol. 125, pp. 542-553, April 2019.

[2] M. Silva Paulo, B. Adam, C. Akagwu, I. Akparibo, R.H. Al-Rifai, S. Bazrafshan, et al., "WHO/ILO work-related burden of disease and injury: Protocol for systematic reviews of occupational exposure to solar ultraviolet radiation and of the effect of occupational exposure to solar ultraviolet radiation on melanoma and non-melanoma skin cancer," Environ. Int., vol. 126, pp. 804-815, May 2019.

[3] A. Modenese, and F. Gobba, "Occupational Exposure to Solar Radiation at Different Latitudes and Pterygium: A Systematic Review of the Last 10 Years of Scientific Literature," Int. J. Environ. Res. Public. Health., vol. 15(1), pp. pii: E375, December 2017.
[4] A. Modenese, and F. Gobba, "Cataract frequency and subtypes involved in workers assessed for their solar radiation exposure: a systematic review," Acta. Ophthalmol., vol. 96(8), pp. 779-788, December 2018.

[5] A. Modenese, and F. Gobba, "Macular degeneration and occupational risk factors: a systematic review," Int. Arch. Occup. Environ. Health., vol. 92(1), pp. 1-11, January 2019.

[6] F. Gobba, A. Modenese, and S.M. John, "Skin cancer in outdoor workers exposed to solar radiation: a largely underreported occupational disease in Italy,” J. Eur. Acad. Dermatol. Venereol., vol. 33(11), pp. 2068-2074, December 2019.

[7] A. Modenese, F. Farnetani, A. Andreoli, G. Pellacani, and F. Gobba, "Questionnaire-based evaluation of occupational and nonoccupational solar radiation exposure in a sample of Italian patients treated for actinic keratosis and other non-melanoma skin cancers," J. Eur. Acad. Dermatol. Venereol., vol. 30(sup.3), pp. 21-26, Apr. 2016.

[8] P. Sartorelli, R. Romeo, V. Paolucci, V. Puzzo, F. Di Simplicio, and L. Barabesi, "Skin photoaging in farmers occupationally exposed to ultraviolet radiation,” Med. Lav., vol. 104(1), pp. 24-29; Febr. 2013.

[9] A. Modenese, L. Korpinen, and F. Gobba, "Solar Radiation Exposure and Outdoor Work: An Underestimated Occupational Risk," Int. J. Environ. Res. Public. Health., vol. 15(10), pp. pii: E2063, Sept. 2018.

[10] A. Modenese, F. Bisegna, M. Borra, C. Grandi, F. Gugliermetti, et al., "Outdoor work and solar radiation exposure: Evaluation method for epidemiological studies,” Med. Pr., vol. 67(5), pp.577-587, Apr. 2016

[11] A. Modenese, F.P. Ruggieri, F. Bisegna, M. Borra, C. Burattini, et al., "Occupational Exposure to Solar UV Radiation of a Group of Fishermen Working in the Italian North Adriatic Sea," Int. J. Environ. Res. Public. Health., vol. 16(16), pp. pii: E3001, August 2019.

[12] M. Wittlich, S. Westerhausen, P. Kleinespel, G. Rifer, and W. Stöppelmann, "An approximation of occupational lifetime UVR exposure: algorithm for retrospective assessment and current measurements," J. Eur. Acad. Dermatol. Venereol. vol. 30 (supp. 3), pp. 27-33, April 2016.

[13] H.R. Moldovan, M. Wittlich, S.M. John, R. Brans, G.S. Tiplica, et al., "Exposure to solar UV radiation in outdoor construction workers usingpersonal dosimetry,"Environ Res., vol.181,pp.108967,Febr. 2020

[14] M. Wittlich, S. M. John, G.S. Tiplica, C.M. Sălăvăstru, A.I. Butacu, et al., "Personal solar ultraviolet radiation dosimetry in an occupational setting across Europe," J. Eur. Acad. Dermatol. Venereol., [epub ahead of print], February 2020.

[15] L. Miligi, A. Benvenuti, P. Legittimo, A.M. Badiali, V. Cacciarini, et al., "Solar ultraviolet radiation risk in outdoor workers: a specific project of Tuscany Region (Italy)," Epidemiol. Prev., vol. 37(1), pp. 51-59, February 2013.

[16] A.M. Siani, G.R. Casale, R. Sisto, A. Colosimo, C.A. Lang, et al., "Occupational Exposures to Solar Ultraviolet Radiation of Vineyard Workers in Tuscany (Italy)," Photochem. Photobiol. Vol. 87, pp. 925-934, August 2011.

[17] International Commission on Non-Ionizing Radiation Protection (ICNIRP), "Icnirp statement - protection of workers against ultraviolet radiation," Health. Phys., vol. 99, pp. 66-87, July 2010.

[18] G. Salvadori, D. Lista, C. Burattini, L. Gugliermetti, F. Leccese, and F. Bisegna, "Sun Exposure of Body Districts: Development and Validation of an Algorithm to Predict the Erythemal Ultra Violet Dose", Int. J. Environ. Res. Public. Health., vol. 16(19), pp.pii: E3632, September 2019.

[19] K. A. Baczynska, M. Khazova, and J.B. O'Hagan JB. "Sun exposure of indoor workers in the UK - survey on the time spent outdoors," Photochem. Photobiol. Sci. vol 18(1), pp. 120-128, January 2019.

[20] L. Miligi, "Ultraviolet radiation exposure: Some observations and considerations, focusing on some Italian experiences, on cancer risk, and primary prevention," Environments, vol. 7(2),pp.10, Febr. 2020.

[21] G. Salvadori, F. Leccese, D. Lista, C. Burattini, and F. Bisegn. "Use of smartphone apps to monitor human exposure to solar radiation: Comparison between predicted and measured UV index values," Environ. Res. vol. 185, pp. 109274, February 2020. 